\title{
Antibiotic Drug Resistance in HIV Seropositive Pregnant Women
}

\author{
Kwashie Ajibade Ako-Nai", Omo-Omorodion B. I. \\ Department of Microbiology, Obafemi Awolowo University, Ile-Ife, Nigeria \\ *Corresponding author: kwasajibad@gamil.com
}

Received January 24, 2019; Revised March 10, 2019; Accepted March 24, 2019

\begin{abstract}
Background: Vaginal infections are often associated with a significant risk of morbidity especially in pregnant women. These infections if left untreated often result in a long-term sequelae and poses a higher adverse pregnancy outcome especially in immunocompromised women. While HIV infection has been reported to be a high risk of pathogenic bacterial colonization, the misuse of antibiotics is high among women in developing countries. Methodology and results: A high vaginal swab was collected from the posterior fornix from each pregnant women by the attending physician using sterile bivalve speculum and a cotton- tipped applicator. Each sample was cultured and identified using standard bacterlogical methods. Selected pathogens were thereafter tested for their sensitivity to 23 commonly prescribed antibiotics using the Kirby-Bauer method. Altogether, 1,156 bacterial isolates were cultured from high vaginal swabs of both 114 HIV seropositive and 126 HIV seronegative pregnant women, averaging 4.81 bacterial per subject each for both cohorts. S. aureus was seen as the single predominant isolate recovered from both groups. In addition, of the $22 S$. aureus recovered from HIV infected women, 10 isolates were Methicillin resistant S. aureus (MRSA) and 12 Methicillin sensitive $S$ aureus (MSSA), while, of the 25 S. aureus recovered from HIV seronegative women, 13 isolates were Methicillin resistant $S$. aureus (MRSA) and 12 Methicillin sensitive $S$ aureus (MSSA). Other gram negative pathogens associated with lower genital infections were also studied. Conclusion: The incidence of multiple antibiotic resistance was high among isolates recovered from both cohorts, which is probably due to uncontrollable ease of access to these antibiotics in the environment where antibiotics restriction/policy is lacking. There is an urgent need for continuous monitoring, health education, drug abuse awareness and implementation of interventions to restrict antibiotic abuse especially among immunocompromised individuals in the study environment.
\end{abstract}

Keywords: bacterial isolates, antibiotics resistance, high vaginal swab, HIV pregnant women

Cite This Article: Kwashie Ajibade Ako-Nai, and Omo-Omorodion B. I., "Antibiotic Drug Resistance in HIV Seropositive Pregnant Women." American Journal of Microbiological Research, vol. 7, no. 2 (2019): 45-50. doi: 10.12691/ajmr-7-2-2.

\section{Introduction}

Women in their reproductive age are most vulnerable to emerging opportunist infections including HIV/AIDS. This challenge is most prominent in sub-Saharan African countries [1] and poses more risk in pregnancy because of hormonal changes and suppressed immune system, [2] which often put these women at risk of various adverse pregnancy complications and outcomes [3].

HIV in pregnancy is a serious life threatening disease. Evidence has shown that in HIV infected women, pre-invasive cervical lesions relating to HIV immunosuppression may be responsible for increased risk of pathogenic bacterial colonization in infected women [4]. This may be a major reason a high proportion of infected women present with pathogens in their lower genitals during clinic tests.

Vaginal infections can be associated with a significant risk of morbidity and mortality especially in pregnant women [5]. These infections often result in a long-term sequelae such as tubal infertility, ectopic pregnancy, reproductive dysfunction and adverse pregnancy outcomes (e.g., preterm labor and delivery and small gestational age, still birth, intrauterine growth retardation) [6] if left untreated. HIV has also been shown to be associated with microbiome shift and immune activation that may affect the outcome of disease progression [7] Antibiotics have been considered the standard treatment of most infections caused by bacteria. They are powerful drugs that destroy or slow down the growth of bacteria.

While HIV infection has been reported to be a high risk of pathogenic bacterial colonization, the misuse of antibiotics to treat these bacterial infection is high among women in low and Medium Income Countries (LMIC) [8]. Furthermore, this misuse of drug provides selective pressure that favours the emergency of resistant bacteria strains [9]. However, the global spread of drug-resistant bacterial pathogens has greatly limited the repertoire of antibiotics available to effectively treat patients. As a result, clinicians are becoming increasingly reliant on 
last-line antimicrobial agents to treat a growing number of common bacterial infections [10]. Furthermore, the beta -lactam is a commonly used antibiotics in treatment of pathogenic infection among pregnant women because of its less fetal toxicity. In addition emergence of resistance has limited its use especially with the methicillin (MRSA) strains which are now multiresistant to other classes of antimicrobials including aminoglycosides, beta-lactams, carbapenems, cephalosporins, floroquinilones and macrolides [10,11]. Similarly, the use of clotrimazole (sulphamethoxazole/ trimethoprim) which is the mainstay for treating opportunistic infections including vaginal colonization with pathogens among HIV infected patients and thus gaining more resistance to bacterial isolates. The efficacy of these agents has also begun to decline in the face of rapidly evolving resistant bacterial population. Studies on antibiotic drug resistance among HIV infected pregnant women are scarce in our environment, hence this study. We therefore designed to study the pattern of antibiotic resistance in bacterial isolates cultured from the vagina of HIV seropositive pregnant women in Akure, Southwest Nigeria. The result we believe will provide meaningful database for clinicians who hither-to lack reliable ones to treat their patients. Such data will be epidemiologically significant to patients better management and recovery.

\section{Methods}

\subsection{Study Centres}

All the participants involved were pregnant women at the third trimester of pregnancy that were fully registered at the antenatal clinics of the selected health care facilities in Akure, South and Ifedore local government areas (LGA) of Ondo State between November 2015-December 2016. Ethical approval for the study was obtained from the ethics committee of the Ondo State Hospitals Management Board. Information relating to each participant was obtained through verbal interview, questionnaire responses and case files managed by the attending physicians.

\subsection{Inclusion Criteria}

All participants who voluntarily consented and thereby had their HIV status confirmed through blood screening at the HIV centre of each clinic were included in the study. There was no age restriction and participants that volunteered were at the third trimester of their pregnancy.

\subsection{Exclusion Criteria}

All those who did not meet the inclusion criteria were excluded.

\subsection{HIV Screening among Cohort}

A $5 \mathrm{~mL}$ volume of whole blood was collected in a sterile vacutte EDTA tubes $\mathrm{K} 3$ and sterile $38 \times 0.8 \mathrm{~mm}$ needles from each participant. A small aliquot was applied onto the HIV-1/2 strip (Determine Test, Alere, London, England, UK) for the preliminary determination of HIV serostatus. Confirmatory test for HIV infection was performed using the Abbott enzyme-linked immunosorbent assay (ELISA) procedure (Abbott Laboratories, Chicago, IL, USA).

\subsection{Isolation and Identification of Bacterial Isolates from High Vaginal Swabs}

A sample of high vaginal swab was collected from the posterior fornix from each pregnant women by the attending physician using sterile bivalve speculum (Changzhou Huankang Medical Devices Co. Ltd, Changzhou City 213116, Jiangsu Province, China) and sterile cotton-tipped applicator (Evepon, Industrial Limited, Onitsha, Anambra State, Nigeria) into freshly prepared sterile thioglycollate medium and incubated at $37^{\circ} \mathrm{C}$ for $24 \mathrm{~h}$ for growth. After growth was observed, a loopful of the sample was streaked initially with the aid of heat- flamed standard aluminium wire loop (delivering $0.001 \mathrm{ml}$ on to freshly prepared agar plates - Blood agar, Proteose peptone agar and Mannitol salt agar). Thereafter, the plates were incubated aerobically at $37^{\circ} \mathrm{C}$ for $24 \mathrm{~h}$ and anaerobically in AnaeroPack jar 2.5 Litre, Order No. 50-25, product of Mitsubishi Gas Chemical Company Co., Inc. Japan (all samples were analysed within 24 hours of collection) for growth. Only plates on which colonies appeared were examined. Each distinct colony appearing on agar plates was picked and further studied. Each colony was classified based on cultural and morphological characteristics such as size, elevation, opacity and colour on media plates. Initial Gram's stain was prepared for each colony and further identification of each colony was based on their reaction on conventional enriched, selective and differential media. Further studies were done on selected pathogens using the API kits used include API 20E and API Staph (bioMéerieux, France).

\subsection{Antibiotic Susceptibility Testing}

All selected bacterial isolates were tested for their sensitivity to 23 commonly prescribed antibiotics using the Kirby-Bauer method. The antibiotics used were obtained from Oxoid (Basingstoke, UK) and included amoxicillin/clavulanic acid AMC $(30 \mu \mathrm{g})$, ampicillin AMP $(10 \mu \mathrm{g})$, penicillin G P (1 IU), oxacillin OX (1 $\mu \mathrm{g})$, ceftriaxone CRO $(30 \mu \mathrm{g})$, cefuroxime CXM $(30 \mu \mathrm{g})$, chloramphenicol C $(30 \mu \mathrm{g})$,imipenem IPM $(10 \mu \mathrm{g})$, tetracycline TE $(30 \mu \mathrm{g})$, erythromycin $\mathrm{E}(15 \mu \mathrm{g})$, gentamycin $\mathrm{CN}(10 \mu \mathrm{g})$, kanamycin $\mathrm{K} \quad(30 \mu \mathrm{g})$, streptomycin $\mathrm{S}(10 \mu \mathrm{g})$, vancomycin VA $(5 \mu \mathrm{g})$, bacitracin BA (10 IU), optochin OPT (5 $\mu \mathrm{g})$, nalidixic acid NA (30 $\mu \mathrm{g})$, ciprofloxacin CIP (5 $\mu \mathrm{g})$, ofloxacin OFX (5 $\mu \mathrm{g})$, nitrofurantoin $\mathrm{F}(300 \mu \mathrm{g})$, fusidic acid FD (5 $\mu \mathrm{g})$, sulphamethoxazole/ trimethoprim SXT $(25 \mu \mathrm{g})$ and mupirocin MUP $(200 \mu \mathrm{g})$. S. aureus ATCC 25923 and Enterobacter aerogenes ATCC 13042 (American Type Culture Collection, Rockville, USA) were used as control organisms. 


\section{Results}

Altogether, 1,156 bacterial isolates were cultured from high vaginal swabs of both 114 HIV seropositive and 126 HIV seronegative pregnant women. Of these isolates, $549(47.5 \%)$ of the recovered bacterial isolates were cultured from HIV seropositive women while 607 (52.5\%) bacterial isolates were cultured from HIV seronegative women. The data obtained from the study also indicated that the mean bacteria per subject for HIV seropositive was $4.81(549 / 114)$ per subject compared to the control 4.81(607/126) per subject from High vaginal swab samples collected. Furthermore, $S$. aureus was seen as the single predominant isolate recovered from both groups accounting 32 for HIV seropositive subjects to $26 \mathrm{~S}$. aureus for HIV seronegative subjects. While, 22 randomly selected $S$. aureus isolates from HIV positive women were tested to the antibiotics studied, $25 \mathrm{~S}$. aureus was also studied for the control group. Similarly, other gram negative pathogens associated with lower genital infections were also studied Table 1.

Table 2 shows the pattern of antibiotic resistant isolates cultured from high vaginal swabs of HIV seropositive pregnant mothers. Of the $22 \mathrm{~S}$. aureus isolates tested, 22 were resistant to penicillin, 21 to ampicillin, 10 to oxacillin and only 4 to augmentin (amoxicillin/clavulanic acid). However, with the two cephalosporins tested, $22(100 \%)$ were resistant to cefuroxime and one isolate was resistant to ceftriaxone. Furthermore, only one isolate was resistant to imipemen. The results showed among the aminoglycoside, 4 of the $S$. aureus isolates tested were resistant to streptomycin, 6 to kanamycin and only one isolate was resistant to gentamycin. Of the $22 \mathrm{~S}$. aureus tested, 13 isolates were resistant to vancomycin, 17 to tetracycline, 8 to chloramphenicol and 13 to erythromycin while all $100 \%$ of $S$. aureus were resistant to nalidixic acid. However, the result also showed only 4 of the 22 isolates tested were resistant to ofloxacin, 3 to ciprofloxacin and one only to nitrofurantoin. Incidentally, 19 of the 22 isolates tested were resistant to bacitracin, 17 to sulphamethoxazole/trimethoprim, 22 to optochin. Only 7 of the 22 isolates tested were resistant to fusidic acid and only 2 to mupirocin. Similar trend of resistance seen with $S$. aureus also occurred for E. coli, Klebsiella pneumoniae and Pseudomonas aeruginosa isolates, where isolates tested were resistant to the following antibiotics: penicillin, ampicillin, oxacillin, augumentin cefuroxime, kanamycin, vancomycin, erythromycin, optochin, bacitracin, fusidic acid and mupirocin.

When compared to Table 3, of the $25 \mathrm{~S}$. aureus isolates tested among HIV seronegative pregnant mothers, all $(100 \%)$ were resistant to ampicillin, cefuroxime, nalidixic acid and optochin while 24 of the isolates were resistant to bacitracin and 23 to penicillin. 14 isolates each were resistant to tetracycline and sulphamethoxazole/trimethoprim, 13 of the $S$. aureus isolates were similarly resistant to oxacillin, 9 to vancomycin, 8 each to fusidic acid and kanamycin. 7 of the isolates were resistant to streptomycin, 5 to ceftriaxone, 4 to erythromycin, 3 of the isolates were also resistant to gentamycin, only 2 isolates each were resistance to ofloxacin and mupirocin and 1 isolate each was resistant to augumentin and nitrofurantoin, none of the isolates were resistant to imipemen. However, similar trend of resistance was seen with E. coli, Klebsiella pneumoniae and Pseudomonas aeruginosa isolates tested were resistant to penicillin, oxacillin, cefuroxime, vancomycin, optochin, bacitracin and fusidic acid understanding the prevalence of resistance among all groups. The distribution of multiple co-resistance of MRSA with other antibiotics among HIV seropositive and seronegative pregnant women is reflected in Figure 1.

Table 1. Distribution of bacterial isolates recovered from HVS of HIV seropositive and seronegative pregnant women

\begin{tabular}{|c|c|c|c|}
\hline Bacterial isolates & HIV seropositive $(n=114)$ & HIV seronegative $(n=126)$ & \\
\hline & Total No(\%) of bacterial isolates recovered & Total No(\%) of bacterial isolates recovered & $\mathrm{P}$ value $(95 \% \mathrm{CI})$ \\
\hline \multicolumn{4}{|l|}{ Gram positive cocci } \\
\hline Pathogenic $S$. aureus & $32(5.8)$ & $26(4.3)$ & \\
\hline Coagulase negative Staphylococci & $176(32.1)$ & $279(45.9)$ & $0.012(2.5-9.5)$ \\
\hline Gram-ve cocci & $5(0.9)$ & $2(0.3)$ & \\
\hline \multicolumn{4}{|l|}{ Gram +rods } \\
\hline Spore formers & $2(0.3)$ & $20(3.3)$ & $0.140(1.1-2.6)$ \\
\hline Non spore formers & $222(40.4)$ & $214(35.3)$ & $0.618(2.4-3.9)$ \\
\hline \multicolumn{4}{|l|}{ Gram-ve rods } \\
\hline Lactose fermenters & $49(8.9)$ & $40(6.6)$ & $0.552(2.8-4.8)$ \\
\hline Non lactose fermenters & $63(11.5)$ & $26(4.3)$ & $0.055(0.1-9.3)$ \\
\hline Total & $549(47.5)$ & $607(52.5)$ & \\
\hline
\end{tabular}

Table 2. Pattern of antibiotic resistant isolates cultured from high vaginal swabs (HVS) of HIV seropositive pregnant mothers

\begin{tabular}{|c|c|c|c|c|c|c|c|c|c|c|c|c|c|c|c|c|c|c|c|c|c|c|c|c|}
\hline \multirow[t]{2}{*}{ Bacterial Isolates } & \multirow{2}{*}{$\begin{array}{c}\text { Total No of } \\
\text { isolates tested }\end{array}$} & \multicolumn{23}{|c|}{ Antibiotics to which isolates from HIV seropositive pregnant mothers were resistant } \\
\hline & & $\mathrm{P}$ & $\overline{\mathrm{AMP}}$ & $\mathrm{OX}$ & A & $\mathrm{XXM}$ & & IPM & $\mathrm{S}$ & $\mathrm{K}$ & $\mathrm{CN}$ & VA] & TET & $\mathrm{C}$ & $\mathrm{E}$ & NA & $\overline{\mathrm{OF}}$ & CIP & $\mathrm{F}$ & OPT & $\mathrm{BA}$ & SXT & FD & $\overline{\text { MUP }}$ \\
\hline $\begin{array}{l}\text { Staphylococcus } \\
\text { aureus } \\
\text { Gram negative rods }\end{array}$ & 22 & 22 & 21 & 10 & 4 & 22 & 1 & 0 & 4 & 6 & 1 & 13 & 17 & 8 & 13 & 22 & 4 & 3 & 1 & 22 & 19 & 17 & 7 & 2 \\
\hline Escherichia coli & 4 & 4 & 4 & 4 & 4 & 4 & 2 & 0 & 3 & 4 & 1 & 4 & 3 & 3 & 4 & 3 & 2 & 1 & 3 & 4 & 4 & 3 & 4 & 4 \\
\hline $\begin{array}{l}\text { Klebsiella } \\
\text { pneumoniae }\end{array}$ & 2 & 2 & 2 & 2 & 2 & 2 & 1 & 1 & 2 & 1 & 0 & 2 & 2 & 2 & 2 & 0 & 2 & 0 & 2 & 2 & 2 & 2 & 2 & 2 \\
\hline $\begin{array}{l}\text { Pseudomonas } \\
\text { aeruginosa }\end{array}$ & 5 & 5 & 5 & 5 & 5 & 5 & 1 & 0 & 4 & 4 & 0 & 5 & 2 & 3 & 5 & 3 & 2 & 0 & 5 & 5 & 5 & 3 & 5 & 5 \\
\hline Total & 33 & 33 & 32 & 21 & 15 & 33 & 5 & 1 & 13 & 15 & 2 & 24 & 24 & 16 & 24 & 28 & 10 & 4 & 11 & 33 & 30 & 25 & 18 & 13 \\
\hline
\end{tabular}

Legend $=\mathrm{OFX}=$ ofloxacin, $\mathrm{OPT}=$ optochin, $\mathrm{BA}=$ bacitracin, $\mathrm{SXT}=$ sulphamethoxazole/Trimethoprim, $\mathrm{MUP}=$ mupirocin, $\mathrm{IPM}=\mathrm{imipemen}, \mathrm{FD}=$ fusidic acid, $\mathrm{AUG}=$ augumentin, $\mathrm{P}=$ penicillin $\mathrm{G}, \mathrm{CXM}=$ cefuroxime, $\mathrm{CIP}=$ ciprofloxacin, $\mathrm{E}=$ erythromycin, $\mathrm{CRO}=$ ceftriaxone, $\mathrm{S}=\mathrm{streptomycin}, \mathrm{VAN}=\mathrm{vancomycin}$, $\mathrm{F}=$ nitrofurantoin, $\mathrm{TET}$, tetracycline, $\mathrm{NA}=$ nalidixic acid, $\mathrm{AMP}=$ ampicillin, $\mathrm{K}=$ kanamycin, $\mathrm{C}=$ chloramphenicol, $\mathrm{CN}=$ gentamicin, $\mathrm{OX}=$ oxacillin. 
Table 3. Pattern of antibiotic resistant isolates cultured from high vaginal swabs of HIV seronegative pregnant mothers

\begin{tabular}{|c|c|c|c|c|c|c|c|c|c|c|c|c|c|c|c|c|c|c|c|c|c|c|c|c|}
\hline \multirow[t]{2}{*}{ Bacterial Isolates } & \multirow[t]{2}{*}{$\begin{array}{c}\text { Total No of } \\
\text { isolates tested }\end{array}$} & \multicolumn{23}{|c|}{ Antibiotics to which isolates from HIV seronegative pregnant mothers were resistant } \\
\hline & & $\mathrm{P}$ & AMP & OX & AUG & CXN & $\mathrm{CRO}$ & IPM & $\mathrm{S}$ & K & $\mathrm{CN}$ & VAN & TET & $\mathrm{C}$ & E I & NA & OFX & CIP & & OPT & BA & SXT & FD & MUP \\
\hline $\begin{array}{l}\text { Staphylococcus } \\
\text { aureus }\end{array}$ & 25 & 23 & 25 & 13 & 1 & 25 & 5 & 0 & 7 & 8 & 3 & 9 & 14 & 6 & 4 & 25 & 2 & 0 & 1 & 25 & 24 & 14 & 8 & 2 \\
\hline \multicolumn{25}{|l|}{ Gram negative rods } \\
\hline Escherichia coli & 7 & 7 & 6 & 7 & 6 & 7 & 2 & 0 & 2 & 0 & 1 & 7 & 6 & 2 & 5 & 4 & 0 & 1 & 0 & 7 & 7 & 3 & 7 & 3 \\
\hline $\begin{array}{l}\text { Klebsiella } \\
\text { pneumoniae }\end{array}$ & 5 & 5 & 5 & 5 & 5 & 5 & 0 & 0 & 3 & 3 & 2 & 5 & 4 & 4 & 3 & 4 & 1 & 3 & 2 & 5 & 5 & 4 & 5 & 1 \\
\hline $\begin{array}{l}\text { Pseudomonas } \\
\text { aeruginosa }\end{array}$ & 5 & 5 & 5 & 5 & 4 & 5 & 3 & 0 & 5 & 4 & 4 & 5 & 5 & 2 & 3 & 3 & 3 & 1 & 3 & 5 & 5 & 4 & 4 & 5 \\
\hline Total & 42 & 40 & 41 & 30 & 16 & 42 & 10 & 0 & 17 & 15 & 10 & 26 & 29 & 14 & 15 & 36 & 6 & 5 & 6 & 42 & 41 & 25 & 24 & 11 \\
\hline
\end{tabular}

Legend $=\mathrm{OFX}=$ ofloxacin, $\mathrm{OPT}=$ optochin, $\mathrm{BA}=$ bacitracin, $\mathrm{SXT}=$ sulphamethoxazole/Trimethoprim, $\mathrm{MUP}=$ mupirocin, $\mathrm{IPM}=\mathrm{imipemen}, \mathrm{FD}=$ fusidic acid, $\mathrm{AUG}=$ augumentin, $\mathrm{P}=$ penicillin $\mathrm{G}, \mathrm{CXM}=$ cefuroxime, $\mathrm{CIP}=$ ciprofloxacin, $\mathrm{E}=$ erythromycin, $\mathrm{CRO}=$ ceftriaxone, $\mathrm{S}=$ streptomycin, $\mathrm{VAN}=$ vancomycin, $\mathrm{F}=$ nitrofurantoin, $\mathrm{TET}$, tetracycline, $\mathrm{NA}=$ nalidixic acid, $\mathrm{AMP}=$ ampicillin, $\mathrm{K}=$ kanamycin, $\mathrm{C}=$ chloramphenicol, $\mathrm{CN}=\mathrm{gentamicin}$, $\mathrm{OX}=$ oxacillin.

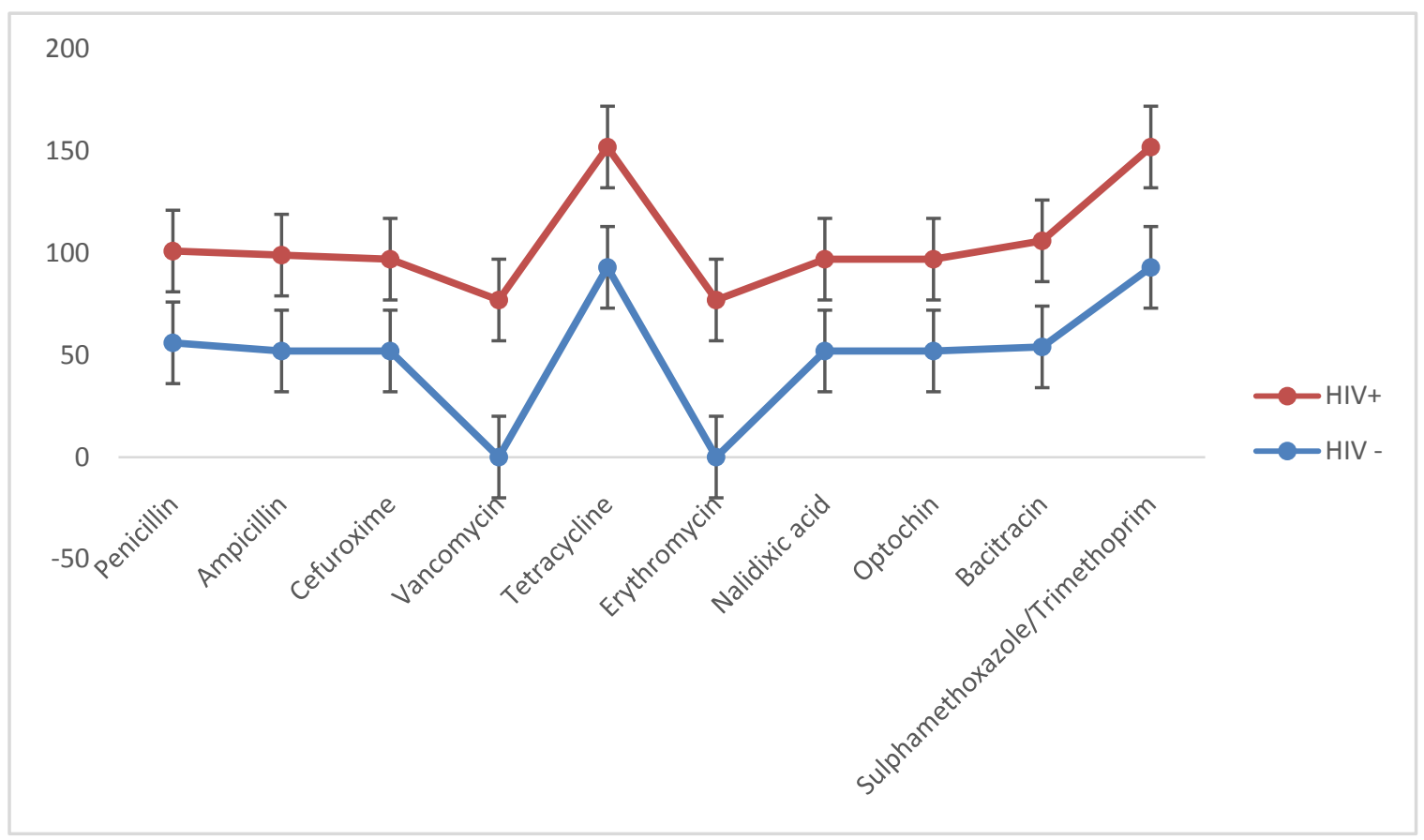

Figure 1. Distribution of multiple antibiotic resistant methicillin $S$. aureus strains cultured from high vagina swabs of HIV seropositive and HIV seronegative pregnant women

\section{Discussion}

The study compared the antibiotic susceptibility of the major pathogens isolated from high vaginal swabs of HIV infected pregnant women to 23 different antibiotics across varying classes of antibiotics used in our clinics. Our data showed that the majority of the isolates recovered from high vaginal swabs of both HIV positive and negative patients were resistant to the beta lactams, optochin and bacitracin antibiotics used. Similarly, the majority of the isolates tested were sensitive to carbapenem (imipemen).

Antibiotic resistance in previous studies have reported that colonization of HIV patients with $S$. aureus and subsequent clinical infections $[12,13]$ may be associated with the site of colonization which plays a key risk factor [14]. The study also reported that the multiple antibiotic resistance (MAR) index of their tested isolates showed that $93.5 \%$ of the isolates from HIV seropositive individuals were above 0.2 , suggesting an antibiotic pressurized community [15]. This corroborates our present study that revealed all bacterial test isolates were $100 \%$ resistant to penicillin, ampicillin, cefuroxime, nalidixic acid and optochin for both HIV seropositive and seronegative pregnant women. This observation confirms that the abuse of antibiotics in this environment is high. However, while most organisms seem resistant to most of the antibiotics employed, the majority of these drugs are often sold without doctors prescription. However, studies have also proved that the mechanism of antibiotics resistance are linked to elaboration of enzymes such as the transpeptidase and carboxypeptidase and the expression of both resistance genes and virulence genes that modify antibiotics and host cells [16]. Unfortunately, this mechanism is by- passed by resistant strains which continuously express resistant genes even in the presence of beta- lactam antibiotics. It is easier for an organism to elaborate enzymes and express both resistant and virulent genes, when host cell are continuously being exposed and pressurised by antibiotics as a result of misuse. Furthermore, the misuse of these antibiotics have been reported to be associated with the mode/ route of drug administration. Our study showed that of the $22 S$. aureus isolates recovered from HIV infected women, ten (10) isolates were Methicillin resistant S. aureus (MRSA) and 
12 Methicillin sensitive $S$ aureus (MSSA), while, of the $25 \mathrm{~S}$. aureus recovered from HIV seronegative women, 13 isolates were Methicillin resistant S. aureus (MRSA) and 12 Methicillin sensitive $S$ aureus (MSSA). Studies on MRSA have shown that virulence among MRSA may not be different from virulence linked with MSSA, but that MRSA poses a greater treatment challenge because it is often multi- drug resistant (MDR) with other classes of antibiotics [16].

While MRSA is of special concern in regard to treatment, the majority of the strains studied have been reported to be resistant to the beta-lactams because of the production of beta-lactamase enzymes and/or possession of intrinsic resistance with alterations in penicillin-binding proteins [17]. MRSA isolates have also been known to show high resistance to erythromycin, clindamycin, aminoglycosides, fluoroquinolones, co-trimoxazole and rifampin. Our study showed a wide range of resistance to most of these antibiotics including the betalactams $(22(100 \%), 21(95.5 \%)$ for penicillin and Ampicillin respectively), macrolides (13(59\%)) and cotrimaxozole $(17(77.3 \%)$ amongst the HIV seropositive pregnant women and betalactams (22(100\%), 21(95.5\%) for penicillin and Ampicillin respectively), macrolides $(13(59 \%))$ and cotrimaxozole $(17(77.3 \%)$ mong the HIV seronegative pregnant women. It is interesting that our study suggests that antibiotic resistance pressure cuts across all pregnant women irrespective of their HIV serostatus because of no restriction/policy of antibiotics consumption in our study environment. However, this pressure poses a greater risk to HIV seropositive pregnant women because of a dual immunosuppression. Additionally, while the some MRSA stains have also been reported to be susceptible to clindamycin and gentamycin in some studies [18], however our study showed a similar susceptibility pattern for both HIV seropositive and seronegative pregnant women with regard to gentamycin, ciprofloxacin and imipenem. Our previous studies however showed effectiveness of these microbials in the treating of bacterial infection [19]. The reason for less resistance to gentamycin was reported to be associated with low abuse of these antibiotics because of the mode of administration and cost of the drug [20]. This study further suggests that while the beta lactams antibiotics are easy to administer and less expensive, the gentamycin and imipenem abuse is low because of its cost and mode of administration.

Furthermore, vancomycin continues to be the drug of choice for treating most MRSA infections caused by multi-drug resistant strains [21]. Most strains of MRSA are inhibited by concentrations of vancomycin ranging from $0.5-2.0 \mathrm{mcg} / \mathrm{mL}$, although strains have been reported with intermediate sensitivity $(\mathrm{MIC}=8 \mathrm{mcg} / \mathrm{mL}$ ) that have been called glycopeptide-intermediate Staphylococcus aureus (GISA) or vancomycin-intermediate Staphylococcus aureus (VISA). On the contrary, results from our study showed that more than half of the total $S$. aureus strains tested, 13(59\%) were resistant to vancomycin for HIV seropositive pregnant women compared to $9(36 \%)$ from HIV seronegative pregnant women. Similarly, $59 \%$ of the $S$. aureus strains were resistant to erythromycin while $16 \%$ of the isolates were resistant to the erythromycin from the HIV seronegative women (Figure 1). Studies of
Sampane-Donkor et al had reported that HIV infected patients are common carriers of multi-drug resistant isolates of several pathogenic bacteria including $S$. aureus and $S$. pneumoniae. The authors reported that infections arising in these patients are more likely to be nosocomial introduced and that these patients also received more courses of antibiotics, which are risk factors for antibiotic resistance [22].

More so, our study also revealed that the majority of $P$. aeruginosa isolates showed multiple antibiotic resistance to more than 10 different classes of antibiotics employed (Table $2 \&$ Table 3 ). $P$. aeruginosa has been reported to be implicated in bacterial infection among HIV patients [23]. Multi -drug resistant $P$. aeruginosa isolates have also been reported to possess several mechanisms of antimicrobial resistance, such as over- expression of the intrinsic AmpC- type cephalosporinase, that confers resistance to the cephalosporins. Additionally, Pseudomonas spp has been implicated in resistance to $\beta$ - lactam antibiotics [24,25] because of the expression of an efflux pump that continuously pumps out the beta- lactamase enzyme elaborated. Other studies have reported that the upregulation of the MexAB-OprM or other efflux pumps of the resistance- nodulation- cell division family confers resistance to carbapenems as well as to quinolones, and to a lesser extend to the aminoglycosides and also the inactivation or down-regulation of the outer membrane porin $\mathrm{D}$ (OprD) confers resistance to the carbapemens [26]. In spite of the high degree of resistances among isolates tested to the antibiotics employed, it is interesting to note that $2.1 \%$ of the isolates tested was resistant imipemen for both HIV seropositive and seronegative pregnant women [Table 2, Table 3].

In conclusion, the high colonization of bacterial isolates in the vaginal of both cohort may be due to hormonal changes and to an extent to their personal hygiene. The incidence of multiple resistance which was high among all the isolates recovered from high vaginal swabs of both cohorts is probably due to uncontrollable ease of access to these antibiotics in an environment where antibiotics restriction/policy is poor or lacking. This calls for urgent need for continuous monitoring, health education, drug abuse awareness and implementation of interventions to restrict antibiotic abuse especially among immunocompromised individuals in Nigeria.

\section{Statement of Competing Interests}

Authors declare that there are no competing interests.

\section{References}

[1] Klouman E., Masenga E. J., Klepp K-I et al. HIV and reproductive tract infections in a total village population in rural Kilimanjaro, Tanzania: women at increased risk. J Acquir Immune Defic Syndr Hum Retrovirol, 1997, 14:163-168.

[2] Sewankambo N., Gray R. H., Wawer M. J. et al. HIV-1 infection associated with abnormal vaginal flora morphology and bacterial vaginosis. Lancet, 1997, 350:546-550.

[3] French R., Brocklehurst P. The effect of pregnancy on survival in women infected with HIV a systematic review of literature and meta-analysis. British journal of Obstetrics and Gynaecology, 1998, 105: 827-835. 
[4] Leroy V., De Clerq A, Ladner J. et al. Should screening of genital infections be part of antenatal care in areas of high HIV prevalence? Genitourin Med, 1995, 71(4): 207-211.

[5] John G. C., Nduati R. W., Mbori-Ngacha D. et al. Genital shedding of human immunodeficiency virus type-1 DNA during pregnancy: association with immunosuppression, abnormal cervical and vaginal discharge and severe vitamin A deficiency. J Infect Dis, 1997, 175(1): 57-62.

[6] Brocklehurst P., French R. The association between maternal HIV infection and perinatal outcome: a systematic review of the literature and meta-analysis. British Journal of Obstetrics and Gynaecology, 1998, 105: 839-848.

[7] Brenchley J. M., Douek D. C. Microbial translocation across the GI tract. Annu Rev Immunol 2012; 30: 149-73.

[8] Iroha I., Nwakeze E., Ejikeugwu C., Oji A., Udu-Ibiam E., et al. Frequency and antibiogram of uropathogens isolated from urine samples of HIV infected patients on ART. Am J Biosc 2013; 1: 50-53.

[9] Adegoke A. A., Tom Mvuyo, Okoh A., Steve J. Studies on multiple antibiotic resistant bacteria isolated from surgical site infections. Scientific Research and Essays 2010; 5: 3876-3881.

[10] Mesaros N., Nordmann P., Plésiat P., Roussel-Delvallez M., Van Eldere J, Glupczynski Y, et al. Pseudomonas aeruginosa: Resistance and therapeutic options at the turn of the new millenium. Clin Microbiol Infect. 2007; 13: 560-78.

[11] Olanike O. K. and Babatunde E. O. The Pattern of Antibiotic use in an Urban Slum in Lagos State, Nigeria. West African Journal of Pharmacy, 2013, 24(1) 49-57. 12 .

[12] Philip P. J., John T., Sigrid K., Brandi L., Lowery H. K.. Resistant Staphylococcus aureuscolonization of the groin and risk of clinical infection among HIV infected adults. Emerging Infectious Diseases 2013; 19: 4.

[13] Hidron A. I., Kempker R., Moanna A., Rimland D. Methicillinresistant Staphylococcus aureus in HIV-infected patients. Infect Drug Resist 2010; 3: 73-86.

[14] Ako-Nai K. A., Adeyemi F. M.., Adejuyigbe E., Ebhodaghe B. I., Osho P. O., Oyeniyi T. T., Kassim O. O. The Dynamics of Bacteria Population on the Skin, Throat and Gastrointestinal tract of HIV Seropositive Patients. Annals of Tropical Medicine and Public health 2015; 8(5):164-176.

[15] Magiorakos A. P., Srinivasan A., Carey R. B., Carmeli Y., Falagas M. E. Multidrug resistant, extensively drug-resistant and Pan drug resistant bacteria: An International expert proposal for interim standard definitions for acquired resistance. ClinMicrobiol Infect 2012; 18: 268-281.

[16] Frank-Peterside N., Chukwugozim R., Okerentugha P. O. HIV-1-2 co-infection with multidrug resistant (MDR) uropathogens in Portharcourt, Nigeria. Nature and Science 2013; 11: $11-20$.

[17] Livermore D.M. Penicillin-binding proteins, porins and outer-membrane permeability of carbenicillin-resistant and -susceptible strains of Pseudomonas aeruginosa. J Med Microbiol 1984; 18: 261-70.

[18] Ako-Nai K. A., Makun C. I., Omo-Omorodion B. I. Resistant Bacterial agents in HIV-seropositive Pregnant Women. World Journal on Pharmaceutical Research 2019; 8(2): 167-179.

[19] Adeyemi F. M., Akonai K. A., Oyemiyi T. T., Kassim O. O., Blessing I. E., et al. (2015) Molecular characterization and antibiotic resistance profiles of bacterial isolates cultured from HIV seropositive patients. Archives of Clinical Microbiology 6: $1-12$.

[20] Ebhodaghe, B. I., Ako-Nai K. A. and Aderoba A. K. Evaluation of risk factors in MTCT among HIV-seropositive pregnant women in selected centres in Akure, South western Nigeria. Annals of tropical medicine and public health 2017; 10(1): 165-181.

[21] M. F. Cotton, E. Wasserman, J. Smit, A. Whitelaw, and H. J. Zar, "High incidence of antimicrobial resistant organisms including extended spectrum beta-lactamase producing Enterobacteriaceae and methicillin-resistant Staphylococcus aureus in nasopharyngeal and blood isolates of HIV-infected children from Cape Town, South Africa," BMC Infectious Diseases, vol. 8, article 40, 2008.

[22] Murugesh K., Deepa S., Venkatesha D. Multi drug resistant uropathogens in HIV: Are they a threat to community. Int $J$ Scientific Study 2014; 2: 38-42.

[23] Adeyemi A. I., Sulaiman A. A., Solomon B. B., Chinedu O. A., Victor I. A. Bacterial Bloodstream Infections in HIV-infected adults attending a Lagos teaching hospital. J Health Popul Nutr 2010; 28: 318-26.

[24] Abujnah A. A., Zorgani A., Sabri M. A., El-Mohammady H., Khalek R. A., Ghenghesh K. S. Multidrug resistance and extendedspectrum b-lactamases genes among Escherichia coli from patients with urinary tract infections in Northwestern Libya. Libyan J Med 2015; 2(10): 26412.

[25] Tomás M., Doumith M., Warner M., Turton J. F., Beceiro A., Bou G., et al. Efflux pumps, OprD porin, AmpC beta-lactamase, and multiresistance in Pseudomonas aeruginosa isolates from cystic fibrosis patients. Antimicrob Agents Chemother 2010; 54: 2219-24.

[26] Joly-Guillou M. L., Kempf M., Cavallo J. D., Chomarat M., Dubreuil L., Maugein J., et al. Comparative in vitro activity of Meropenem, Imipenem and Piperacillin/tazobactam against 1071 clinical isolates using 2 different methods: a French multicentre study. BMC Infect Dis 2010; 10: 72. 